\title{
Short Communication: Identification and characterization of multiple splicing forms of bovine prochymosin mRNA
}

\author{
N. Zinovieva, $†$ † M. Müller*, G. Brem¥’§ \\ *Institute of Animal Breeding and Genetics, University of Veterinary Medicine, Vienna, Austria \\ †All-Russian Research Institute of Animal Breeding, Department of Biotechnology, Dubrowitzy, Podolsk District, \\ Moscow Region 142132, Russia \\ ‡Institute of Agricultural Biotechnology, Department of Animal Biotechnology, Tulln, Austria \\ $\S$ Ludwig Boltzmann Institute of Immuno-, Cyto- and Molecular Genetic Research, Vienna, Austria
}

\begin{abstract}
Bovine prochymosin (bPC) is an inactive precursor of the milk clotting enzyme chymosin (EC 3.4.23.4), that is present in the abomasum of suckling calves. We investigated the pattern of bPC mRNA expression in the calf stomach tissues by RT-PCR assay and sequence analysis of cloned RT-PCR products. We identified multiple isoforms appearing due to alternative splicing of $\mathrm{bPC}$ mRNA. Alternative mRNA forms were generated by skipping one to four full exons within the bPC gene. Various splicing events resulted in seven bPC transcripts, which are 99, 114, 213, 237, 336, 351 and 450 nucleotides shorter compared to full-length mRNA. Analysis of amino acid sequences deduced from alternatively spliced mRNA sequences showed no amino acid transversions and no protein reading frame shift for any splice forms.
\end{abstract}

(Key words: alternative splicing, bovine chymosin, exon skipping)

Abbreviation key: $\mathbf{b P C}=$ bovine prochymosin; $\mathbf{N T}=$ nucleotide; $\mathbf{R T}=$ reverse transcription.

Bovine prochymosin (bPC) (365 AA, $\mathrm{Mr}=40777)$ is an inactive precursor of the predominant milk-clotting enzyme chymosin (rennin, EC 3.4.23.4), which is present in the fourth stomach of suckling calves (Foltman et al., 1979). bPC is synthesized by mucosal cells as a preprochymosin (381 AA, $\mathrm{Mr} \approx 43000$ ) with a 16 AA hydrophobic signal peptide (Moir et al., 1982). The enzyme chymosin (323 AA, $\mathrm{Mr}=35600$ ) is formed by autocatalytic activation at $\mathrm{pH} 4$ to 5 , resulting in cleavage of a $42 \mathrm{AA}$ fragment at the amino terminal end of prochymosin (Foltman et al., 1977). Activation of prochymosin at $\mathrm{pH}<2.5$ results in formation of the enzyme pseudochymosin (338 AA) by

Received February 7, 2002.

Accepted May 6, 2002.

Corresponding author: Dr. Natalia Zinovieva; e-mail: nata@ podolsk.ru. proteolytic cleavage of the 27-28 AA band (Pedersen et al., 1979). The complete AA sequence of bPC was described by Foltman et al. (1977). Later a bPC cDNA sequence was reported (Harris et al., 1982; Nishimori et al., 1982; Moir et al., 1982). Hidaka et al. (1986) determined that the bPC gene was $10.5 \mathrm{~kb}$ and includes 9 exons. The aim of this study was to investigate the splicing of bPC mRNA in stomach tissues of suckling calves and to determine the nucleotide (NT) sequences of all putative isoforms.

The stomach tissues were derived from two unrelated suckling calves. Total RNA was extracted by the method described by Chomczynski and Sacchy (1987). Northernblot analysis was performed using a standard protocol (Ausubel et al., 1994). A bPC cDNA fragment of $0.5 \mathrm{~kb}$, including complete exons 5,6 , and 7 , was used as a probe. Reverse transcription (RT) was performed with $200 \mathrm{ng}$ of total calf stomach RNA, the Superscript II RNase $\mathrm{H}$ - reverse transcriptase (Life Technologies, Vienna) and

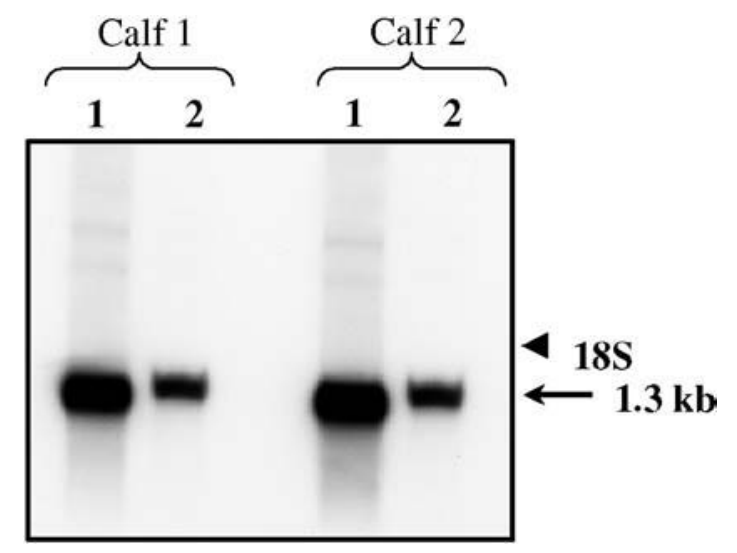

Figure 1. Northern blot analysis of the bPC mRNA from calf stomachs. $3 \mu \mathrm{g}$ polyA RNA and $20 \mu \mathrm{g}$ total RNA (lanes 1 and 2 , respectively) prepared from the stomach tissues of two unrelated suckling calves were hybridized with the $0.5 \mathrm{~kb}$ bPC cDNA-specific probe at $65^{\circ} \mathrm{C}$ overnight. Exposition time was $2 \mathrm{~h}$. Only one signal of the expected length $(1.3 \mathrm{~kb})$ was detected. Longer exposure of the blot (18 h) did not reveal additional bands (data not shown). The position of the 18S rRNA is indicated. 
Table 1. Primer sequences and their localization in the prochymosin gene.

\begin{tabular}{llll}
\hline Primer & Sequence $\left(5^{\prime} \rightarrow 3^{\prime}\right)$ & Localization & Accession No. (positions) \\
\hline R1 & ggt gct act tgc tgt ctt cg & exon 1 & M14069 (213-232) \\
RS9 & aca tgt gtg cat gtg tgt gtg c & exon 9 & M14077 (189-210) \\
RS8 & cat ttt gcc att gat ctc aa & exon 8 & M14076 (57-76) \\
RS79 & aga agc cct ggt c / ct cac c & exon 9 / exon 7 & M14077 (11-23) / M14075 (150-155) \\
\hline
\end{tabular}

Oligo $(\mathrm{dT})_{18}$ as a primer (NEB, England) at $42^{\circ} \mathrm{C}$ for 60 min. For PCR, one forward (R1) and three reverse primers (RS9, RS8, RS79) were designed (Table 1). Initial denaturation at $95^{\circ} \mathrm{C}$ for 5 min was followed by 35 cycles of PCR performed under the following conditions: $94^{\circ} \mathrm{C}$ for $1 \mathrm{~min}, 58^{\circ} \mathrm{C}$ for $1 \mathrm{~min}, 72^{\circ} \mathrm{C}$ for $1 \mathrm{~min}$. The amplified products were separated by PAGE in a $4 \%$ nondenatur- ing gel in TBE buffer and stained with ethidium bromide. PCR fragments were transferred onto a nylon membrane (Hybond $\mathrm{N}+$ ) using a semidry electroblotting device (BioRad). The hybridization was performed with the same probe as for the Nothern-blot analysis. The amplified fragments were cloned into the PCR ${ }^{\mathrm{TM}} \mathrm{II}$ vector (Invitrogen) for sequence determination. The sequencing
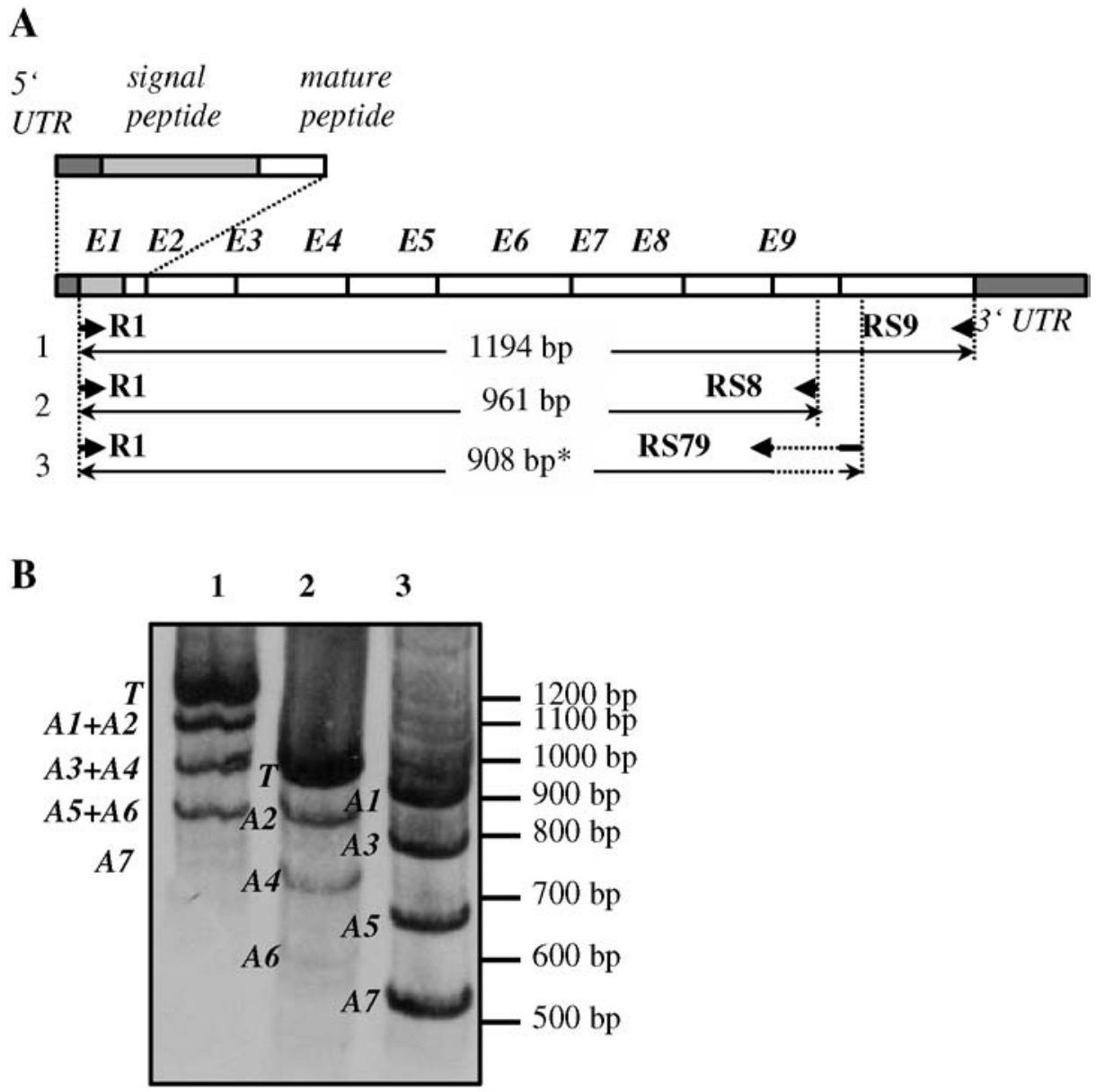

Figure 2. Expression pattern of bPC mRNA in the stomach tissues of suckling calves. (A) Localization of bPC cDNA specific primers used in the RT-PCR-hybridization analysis of calf stomach RNA. Exons marked from E1 to E9 corresponding to their number are shown as boxes. The sequences of $5^{\prime}$ and $3^{\prime}$ UTR are indicated as a dark gray boxes, mRNA region, coding for signal peptide is shown as a light gray box. Positions of three primer sets $(1,2,3)$ used for RT-PCR, as well as the length of the amplified fragments, corresponding to the full-length transcripts are indicated. The bPC cDNA fragment amplified if exon 8 is not present, is marked with an asterisk. (B) RT-PCRhybridization analysis of bPC mRNA. RT-PCR products corresponding to the full-length bPC transcript are marked with $T$. Bands, which are not predicted by primer design are marked with A1-A7 according to decrease of their length. Positions of the DNA molecular weight marker are shown to the right. The numbers of primer sets on the panel A correspond to the lane numbers on the panel B. 
A

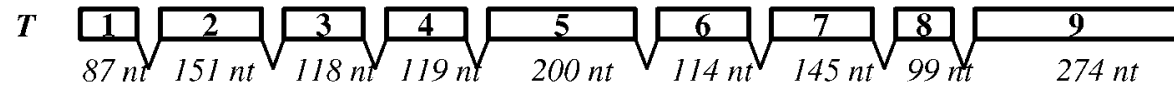

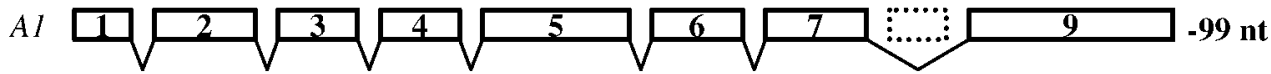

A2

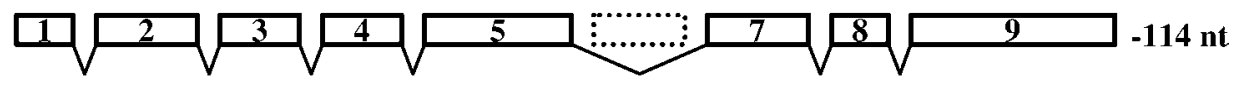

A3

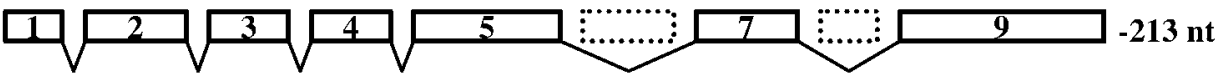

A4

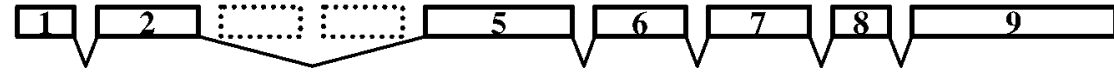

$-237 n t$

A5
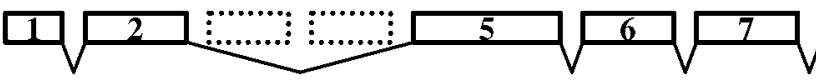

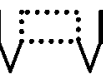

9

$-336 n t$

A6

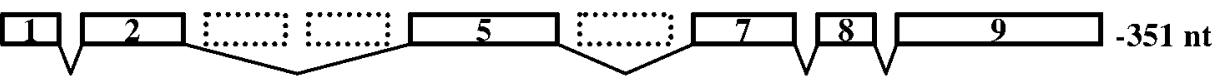

A7
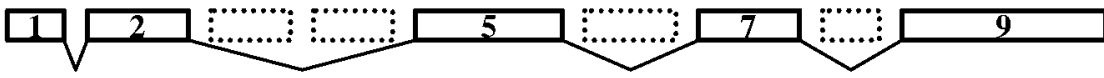

$-450 \mathrm{nt}$

B

$T$

A1-A3

A4-A7

$T$

A1-A3

A4-A7

T

A1-A3

$A 4-A 7$

$T$

A1-A7

$T$

A1, A4, A5

$A 2, A 3, A 6, A 7$

$T$

A1, A3, A5, A7

$A 2, A 4, A 6$

$T$

$A 1, A 3, A 5, A 7$

$A 2, A 4, A 6$

$T$

A1-A7
1 TEITRIPLYKGKSLRKALKEHGLLEDFLQKQQYGISSKYSGFGEVASVPL TEITR IPLYKGKSLRKALKEHGLLEDFLQKQQYGISSKYSGFGEVASVPL TEITRIPLYKGKSLRKALKEHGLLEDFLQKQQYGISSKYSGFGEVASVPL $34 * * *$

51 TNYLDSQYFGKIYLGTPPQEFTVLF DTGSSDFWVPSIYCKSNGCKNHQRF TNYLDSQYFGKIYLGTPPQEFTVLFDTGSSDFWVPSIYCKSNGCKNHQRF TNYLD . . . . . . . . . . . . . . .

101 DPRKSSTFQNLGKPLSIHYGTGSMQGILGYDTVTVSNIVDIQQTVGLSTQ DPRKSSTFQNLGKPLS IHYGTGSMQGI LGYDTVTVSNIVDIQQTVGLSTQ $\ldots \ldots \ldots \ldots \ldots \ldots \ldots \ldots \ldots \ldots \ldots \ldots \ldots \ldots$. . . . . . . .

151 EPGDVFTYAEFDGILGMAYPSLASEYSIPVFDNMMNRHLVAQDLFSVYMD EPGDVFTYAEFDGILGMAYPSLASEYSIPVFDNMMNRHLVAQDLFSVYMD

201 RNGQESMLTLGAIDPSYYTGSLHWVPVTVQQYWQFTVDSVTISGVVVACE RNGQESMLTLGAIDPSYYTGSLHWVPVTVQQYWQFTVDSVTISGVVVACE $\ldots \ldots \ldots \ldots \ldots \ldots \ldots \ldots \ldots \ldots \ldots \ldots \ldots \ldots \ldots \ldots$ SVTISGVVVACE $216 * *$ *

251 GGCQAILDTGTSKLVGPSSDILNIQQAIGATQNQYGEFDIDCDNLSYMPT GGCQAILDTGTSKLVGPSSDILNIQQAIGATQNQYGE . . . . . . . . GGCQAILDTGTSKLVGPSSDILNIQQAIGATQNQYGEFDIDCDNLSYMPT

301 VVFEINGKMYPLTPSAYTSQDQGFCTSGFQSENHSQKWILGDVFIREYYS $\ldots \ldots \ldots \ldots \ldots \ldots \ldots$ DQGFCTSGFQSENHSQKWILGDVFIREYYS VVFEINGKMYPLTPSAYTSQDQGFCTSGFQSENHSQKWILGDVFIREYYS

351 VFDRANNLVGLAKAI

VFDRANNLVGLAKAI

Figure 3. Schematic representation of the multiple splicing forms of bPC mRNAs and predicted AA sequences for alternative bPC transcripts. (A). Seven diverse bPC transcripts generated by skipping of one to four full exons presented. Exons are shown as boxes and marked by 1 to 9 , according to their number. The lacking exons are indicated by dotted line. The full-length bPC mRNA is marked as $T$. Isoforms originating due to alternative splicing are named from $A 1$ to $A 7$, which refers to the RT-PCR products presented on figure $2 \mathrm{~B}$. Decreasing of the length of alternatively spliced bPC mRNAs compared to the full-length transcript is shown to the left. (B). Predicted AA sequences for alternative bPC transcripts. Sequence of full-length bPC (T) is shown in bold. Active aspartate residues Asp-34 and Asp-216 (chymosin numbering) are italicized and are marked with 34 and 216, respectively. AA residues involved in the maintenance of the bilobular structure of chymosin are indicated by asterisks. 
reactions were performed with $500 \mathrm{ng}$ of plasmid DNA, using the LI-COR system (LI-COR, USA).

The expression pattern of bPC mRNA was first analysed by Northern-blot analysis. The samples from both calves showed only one defined signal corresponding to the full-length bPC transcript (Figure 1). The presence of rare bPC mRNA expression products, which might not be detected by Nothern-blot analysis, was investigated by a RT-PCR-hybridization assay using three sets of bPC mRNA specific primers (Figure 2A). Using the first set of primers, the predominant RT-PCR product corresponding to the full-length $\mathrm{bPC}$ mRNA was detected. Furthermore, weaker additional signals of decreased length appeared (Figure 2B, lane 1). To determine the number and the length of these minor transcripts, two additional primer sets (2 and 3 ) were designed (Figure 2A). Since the reverse primer RS8 anneals in the region corresponding to exon 8 of bPC gene, the second set of primers amplifies only cDNAs containing exon 8 . Using the second set of primers we detected four different transcripts (Figure 2B, lane 2), three of them $(A 2, A 4, A 6)$ appear to be generated by alternative splicing of the bPC mRNA. In the third primer set, the reverse primer RS79 anneals to the junction of the exons 7 and 9 and combined with primer R1 amplifies the fragments only if exon 8 is lacking in the transcripts. The amplification of full-length bPC transcript was not expected by this primer set. As it is shown in Figure 2B (lane 3), we could detect four transcripts lacking exon 8. Thus, the RT-PCR method identified seven isoforms of bPC mRNA in addition to the full-length transcript.

To confirm the origin and to determine the structures of the transcripts, sequence analysis of purified RT-PCR products was performed. First, we showed that the predominant mRNA splicing product is the full-length bPC transcript, which is identical with the sequence described by Hidaka et al. (1986). The smaller bPC transcripts were generated by skipping of one to four full exons. The length of bPC mRNAs, detected by sequence analysis was completely in accordance with the length of fragments, visualized by RT-PCR analysis. Schematic representation of the alternatively spliced bPC mRNAs is shown in Figure 3A. The NT sequences of the alternatively spliced bPC mRNAs were submitted to the GenBank Nucleotide Sequence Database under the accession numbers AF421161-AF421167.

Chymosin is a member of the aspartic protease family. It is characterized by two symmetrical domains, which are separated by a deep cleft containing the active residues Asp-34 and Asp-216 (Tang et al., 1978; Gilliand et al., 1990).

Analysis of the AA sequences deduced from the NT sequences of the alternatively spliced bPC mRNAs (Fig- ure 3B) showed no AA transversions and no protein reading frame shift in comparison with chymosin. Four predicted proteins (A4-A7) are characterized by the loss of one (Asp-34) of the catalytic residues, as well as AA residues Thr-35, Ser-37 and NHGly-36, involved in the maintenance of the bilobular structure of chymosin through a network of hydrogen bonds. The other three predicted isoforms (A1-A3) keep both chymosin active Asp residues, and hydrogen bonding AA residues. The proteins predicted from the sequences of alternative $\mathrm{bPC}$ transcripts are $33,38,71,79,112,117$, and $150 \mathrm{AA}$ shorter in length compared to bPC, this corresponds to the calculated Mr of $23.6-36.7 * 10^{3} \mathrm{Da}$.

Moir et al. (1982), when analyzing in vitro translation products of bPC mRNA, identified minor products of unknown origin that were smaller than chymosin. It has been suggested, that these minor products were generated by degradation of bPC. Analyzing the proteins extracted from the calf stomach tissues by Western-blot technique using bovine chymosin specific polyclonal antibodies, we detected weak protein bands of molecular masses of 25 to $35 \mathrm{kDa}$ (data not shown). Based on our sequencing results, we suggest that smaller chymosin forms appear to be generated due to translation of some alternatively spliced bPC mRNA.

\section{REFERENCES}

Ausubel, F. M., R. Brent, R. E. Kingston, D. D. Moore, J. G. Seidman, J. A. Smith, and K. Struhl. 1994. Current protocols in molecular biology. Wiley, New York.

Chomczynski, P., and N. Sacchi. 1987. Single-step method of RNA isolation by acid guanidinum thiocyanate-phenol-chloroform extraction. Anal. Biochem. 162:156-159.

Foltmann, B., V. B. Pedersen, H. Jacobsen, D. Kauffman, and G. Wybrandt. 1977. The complete amino acid sequence of prochymosin. Proc. Natl. Acad. Sci. 74:2321-2324.

Foltmann, B., V. B. Pedersen, D. Kauffman, and G. Wybrandt. 1979. The primary structure of calf chymosin. J. Biol. Chem. 254:8447-8456.

Gilliland, G. L., E. L. Winborne, J. Nachman, and A. Wlodawer. 1990. The three-dimensional structure of recombinant bovine chymosin at 2.3: A resolution. Proteins 8:82-101.

Harris, T. J., P. A. Lowe, A. Lyons, P. G. Thomas, M. A. Eaton, T. A. Millican, T. P. Patel, C. C. Bose, N. H. Carey, and M. T. Doel. 1982. Molecular cloning and nucleotide sequence of cDNA coding for calf preprochymosin. Nucleic Acids Res. 10:2177-2187.

Hidaka, M., K. Sasaki, T. Uozumi, and T. Beppu. 1986. Cloning and structural analysis of the calf prochymosin gene. Gene (Amst.)43:197-203.

Moir, D., J. Mao, J. W. Schumm, G. F. Vovis, B. L Alford, and A. Tauton-Rigby. 1982. Molecular cloning and characterisation of double-stranded cDNA coding for bovine chymosin. Gene (Amst.)19:127-138.

Nishimori, K., Y. Kawaguchi, M. Hudaka, T. Uozumi, and T. Beppu. 1982. Expression of cloned calf prochymosin gene sequence in Escherichia coli. Gene(Amst.)19:337-344.

Pedersen, V., K. Christensen, and B. Foltmann. 1979. Investigations on the activation of bovine prochymosin. Eur. J. Biochem. 94:573-580.

Tang, J., M. N. James, I. N. Hsu, J. A. Jenkins, and T. L. Blundell. 1978. Structural evidence for gene duplication in the evolution of the acid proteases. Nature 271:618-621. 